Research Article

\title{
Flexural Behaviors of Concrete/EPS-Foam/Glass-Fiber Composite Sandwich Panel
}

\author{
Qi Liu, ${ }^{1}$ Wenfeng Du ${ }^{D},{ }^{1}$ Nasim Uddin, ${ }^{2}$ and Zhiyong Zhou' \\ ${ }^{1}$ College of Civil Engineering and Architecture, Henan University, Kaifeng, China \\ ${ }^{2}$ Department of Civil, Construction and Environmental Engineering, University of Alabama at Birmingham, Birmingham, \\ Alabama, USA \\ Correspondence should be addressed to Wenfeng Du; dwf0925@hotmail.com
}

Received 21 August 2018; Accepted 18 September 2018; Published 21 October 2018

Academic Editor: Alexander Kromka

Copyright (C) 2018 Qi Liu et al. This is an open access article distributed under the Creative Commons Attribution License, which permits unrestricted use, distribution, and reproduction in any medium, provided the original work is properly cited.

\begin{abstract}
Composite structural insulated panels (CSIPs) have been developed for structural floor applications instead of traditional structural insulated panels (SIPs). However, the load bearing capacity of CSIPs is low due to the debonding between the top face sheet and the core when they are used for floors. To overcome this drawback, an improved composite structural insulated panel (ICSIP) was proposed and analyzed in this paper. In ICSIPs, a thick layer of concrete is used as the top face sheet instead of glassfiber-reinforced polymer (GFRP) in CSIPs to increase the stiffness of the top compression face sheet. However, the bottom GFRP face sheet and EPS cores in CSIPs are preserved to reduce the weight of the structure and act as a template for the top concrete panels. Full-scale experimental testing and finite-element analysis were conducted to predict the flexural strength and deflection of the ICSIP floor member. Good agreement has been observed between the numerical results and experimental response up to the failure. The cause of failure of ICSIPs is the crushing of concrete face sheet rather than debonding. Moreover, the calculation formula for the ultimate bearing load and deflection was also developed based on the classical sandwich theory. The theoretical predictions reflect well the linear flexural response of the ICSIPs, while deviate as the load increases up to failure due to the theory limitations.
\end{abstract}

\section{Introduction}

The sandwich panels named structural insulated panels (SIPs) were proposed in 1935 by Forest Products Laboratory (FPL) in the United States [1]. And the first large-scale SIPs manufacturing effort appeared in 1959 when Koopers Company converted an automotive production plant in Detroit into a SIP production facility [2]. Then in the mid1980 s, a significant number of manufactures began producing SIPs on a large scale with the improvement of production technology. To date, traditional SIPs have been used for many different applications, such as exteriors wall, roof, floor, and foundation system throughout the world $[3,4]$. SIPs have brought many benefits for the modular panelized construction industry because of characteristics of high quality and precast. However, SIPs still have a lot of drawbacks such as termite attack, low permeability, and weak resistance against wind loading because the oriented strand board (OSB) face sheet is a wood-based composite laminate [5].

To overcome the shortcomings of traditional SIPs, a new composite structural insulated panel (CSIP) was proposed in 2010 [6]. CSIPs utilized low-cost orthotropic thermoplastic glass-fiber-reinforced polymer (GFRP) as face sheets instead of OSB. They can provide much higher strength, stiffness, and creep resistance than traditional ones [7-9]. A comprehensive explanation of CSIP concept, materials characteristics, and manufacturing techniques is proved by Vaidya and Uddin [10]. Mousa and Uddin carried out a series of study in order to determine the global buckling, debonding interfacial tensile stress, critical wrinkling stress, equivalent stiffness, and deflection for CSIPs $[10,11]$. Theoretical and experimental studies have demonstrated that CSIPs are characterized by high strengthto-weight ratio, excellent thermomechanical properties, and superior corrosion resistance. 
However, two drawbacks of CSIPs are still noticeable when they are used as floors or large span roofs. One is the deflection of CSIPs is large relatively in despite of the high strength [10-13]. The elastic modulus of GFRP is comparatively small, which leads to a large deflection of CSIPs. Several investigations show that it is difficult for CSIPs to satisfy the requirements of deflection in building codes if they have the same thickness with concrete floors panel $[14,15]$. The other is the debonding between the compression face sheet and the core. This debonding phenomenon always appears under a small load due to the weak bonding strength of adhesive and low compressive performance of GFRP face sheet, which makes only $17 \%$ of carrying capacity of CSIPs be used $[10,15]$.

An improved composite structural insulated panel (ICSIP) was proposed to expand the application of CSIPs in this study. ICSIPs retains the bottom GFRP face sheet and EPS core in the CSIPs, but recycled aggregate concrete was used as the top face sheet instead of the top GFRP face sheet. The recycled aggregate concrete face sheet has higher compression performance than the GFRP face sheet. Therefore, ICSIPs effectively overcome the problem of large structural displacement and low bearing capacity due to the low compressive performance of the top face sheet in CSIPs. Meanwhile, the recycled aggregate concrete has lower cost than the GFRP, which makes the ICSIPs have more advantageous in terms of production cost than the CSIPs. Similarly, the cost of ICSIPs is still attractive compared to traditional SIP while maintaining the same thickness of EPS core.

The characteristic and manufacturing of ICSIPs were studied in this paper and flexural behaviors of full-scale ICSIP floor members were investigated. In order to understand the load bearing capacity and deflection of the ICSIP floor member, the experimental testing, finite-element analysis, and theoretical evaluation were performed.

\section{Characteristic and Manufacturing of ICSIPs}

2.1. Characteristic of ICSIPs. The concept of ICSIPs is still based on a sandwich structure, in which a soft light-weight thick core is sandwiched between two strong face sheets. The ICSIPs that are developed and evaluated in this research are composed of low-cost orthotropic thermoplastic GFRP laminate as the bottom face sheet, expanded polystyrene (EPS) foam as the core, and recycled aggregate concrete as the top face sheet (Figure 1). The dimension of the ICSIPs is consistent with the traditional CSIPs. The thickness of GFRP face sheet is $3.04 \mathrm{~mm}$ which is the same thickness as the bottom face sheet in the CSIPs. The thickness of the recycled aggregate concrete face sheet is consistent with the EPS core, which can effectively ensure that most of the concrete material is under pressure. Therefore, the thickness of both the recycled aggregate concrete face sheet and the EPS core is $70 \mathrm{~mm}$.

The top face sheet in ICSIPs carries the compressive stress, and the bottom face sheet in ICSIPs carries the tensile stress. However, the core stabilizes the face sheets against buckling and increases the stiffness by holding the face sheets apart. Therefore, structural layout of ICSIPs is

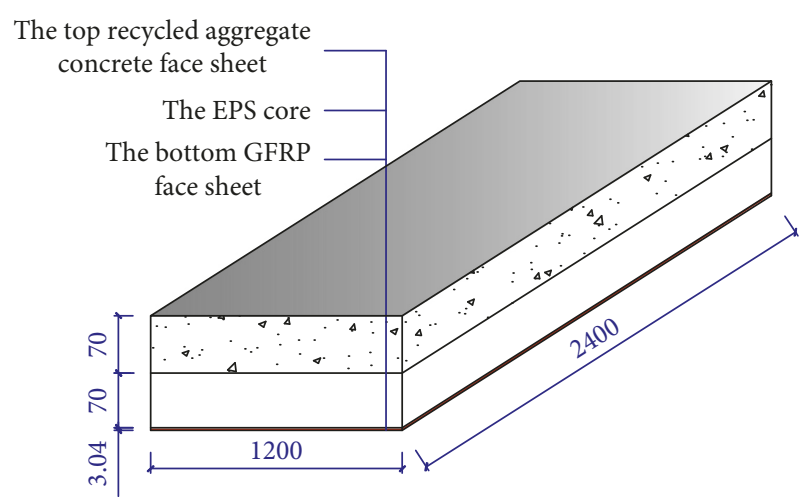

FIgURE 1: Schematic of the ICSIPs (unit: $\mathrm{mm}$ ).

reasonable for GFRP as the bottom face sheet provides high tensile strength, high durability, and fire resistance; EPS as the core are characterized by light weight, thermal insulation, and excellent impact properties, and recycled aggregate concrete as the top face sheet provides high compressive strength and low cost. The assembly of the bottom GFRP face sheet and EPS core can serve as a template for the top concrete face sheet. The application of recycled aggregate concrete reduces the construction waste materials effectively and achieves the purpose of environmental protection. Moreover, ICSIPs have another advantage related to corrosion, for the bottom GFRP face sheet, and the EPS core can prevent moisture entering the cracks in concrete.

Figure 2 illustrates the fabrication process of ICSIPs. The GFRP face sheet is bonded to the EPS core using a hot-melt thermoplastic spray adhesive. Then, the assembly is used as the template supporting the setup of reinforced steel mesh and the cast of concrete. The recycled aggregate concrete can bond with the EPS core naturally during the hardening process of concrete. High-quality and attractive panels can be produced in a short duration by large-scale assembly lines.

2.2. Materials of ICSIPs. The thermoplastic composite bottom face sheet used for ICSIPs consists of 70\% bidirectional glass-fibers impregnated with polypropylene resin. The production of GFRP is directly obtained from the manufacturer with mechanical properties listed in Table 1. The EPS foam core has a high $R$ value, which represents better resistance to the flow of heat. Good thermal resistance property is valuable when CSIPs are used as roof covers. The properties of EPS foam bought from the manufacturer and used in this study are provided in Table 1.

Recycled aggregate concrete is used as the top face sheet. The use of recycled aggregate concrete can not only reduce the construction waste but also decrease the cost. Ordinary Portland cement with a strength of $32.5 \mathrm{MPa}$ and natural river sand fine aggregate with a fineness modulus of 2.67 are used in the recycled aggregate concrete. The recycled coarse aggregate is a commercial concrete with a strength of C20 C40 discarded by a testing station. The concrete was crushed using a small jaw crusher, which produced 


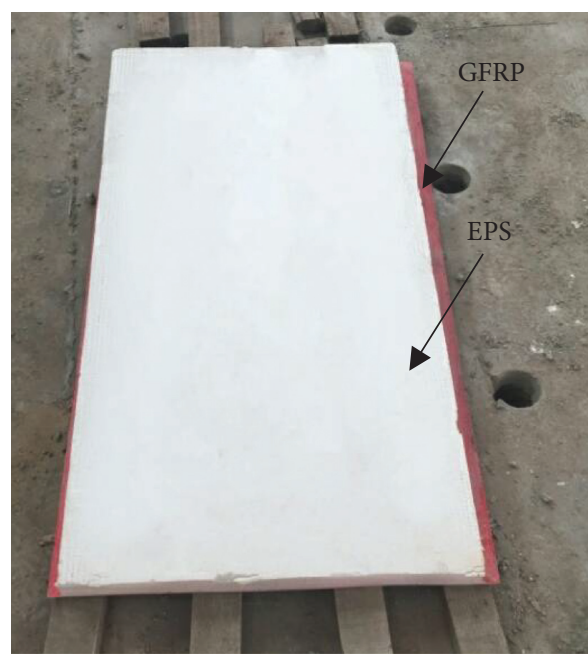

(a)

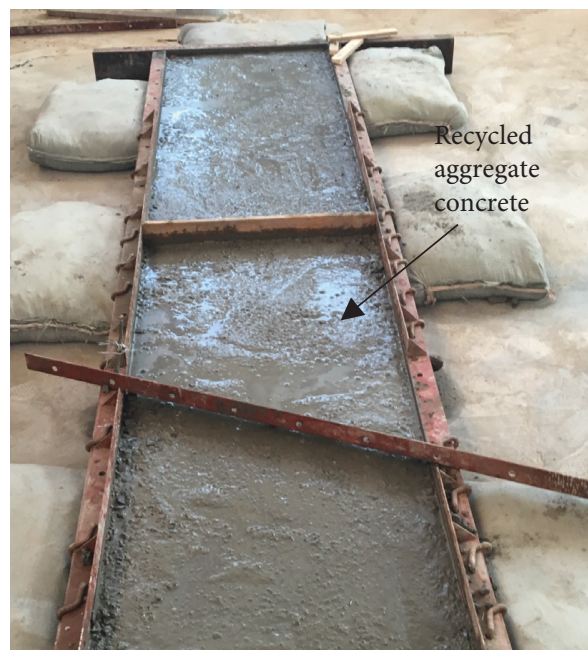

(c)

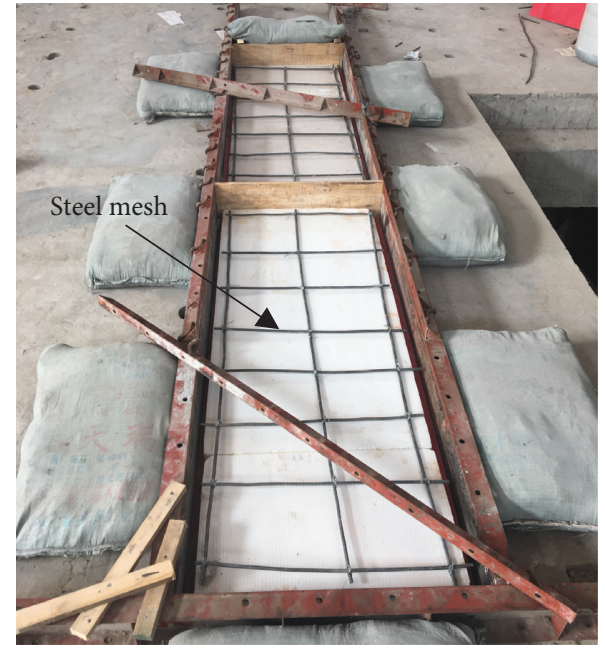

(b)

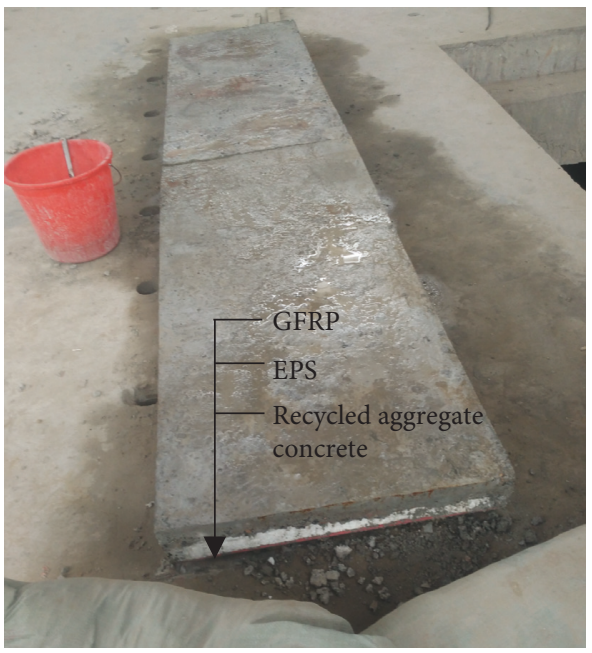

(d)

FIGURE 2: Manufacturing of ICSIPs: (a) the EPS core was bonded on GFRP; (b) steel mesh was setup; (c) the recycled aggregate concrete was cast; (d) a piece of ICSIP was made.

TABLE 1: Mechanical properties of materials.

\begin{tabular}{|c|c|c|c|c|}
\hline Items & Glass-PP face sheet & EPS foam core & $\begin{array}{l}\text { Recycled aggregate } \\
\text { concrete face sheet }\end{array}$ & $\begin{array}{c}\text { Reinforced } \\
\text { steel }\end{array}$ \\
\hline Nominal thickness, $t$ & $3.04 \mathrm{~mm}$ & $70 \mathrm{~mm}$ & $70 \mathrm{~mm}$ & l \\
\hline Density, $\rho_{\mathrm{f}}$ & $980 \mathrm{~kg} / \mathrm{m}^{3}$ & $36 \mathrm{~kg} / \mathrm{m}^{3}$ & $2500 \mathrm{~kg} / \mathrm{m}^{3}$ & $7850 \mathrm{~kg} / \mathrm{m}^{3}$ \\
\hline Weight percentage of glass-fiber & $70 \%$ & l & 1 & l \\
\hline Longitudinal modulus, Ex & $15,169 \mathrm{MPa}$ & $75 \mathrm{MPa}$ & $26 \mathrm{GPa}$ & $206 \mathrm{GPa}$ \\
\hline Transverse modulus, Ey & $15,169 \mathrm{MPa}$ & $75 \mathrm{MPa}$ & $26 \mathrm{GPa}$ & $206 \mathrm{GPa}$ \\
\hline Thickness direction modulus, $\mathrm{Ez}$ & $1050 \mathrm{MPa}$ & $75 \mathrm{MPa}$ & $26 \mathrm{GPa}$ & $206 \mathrm{GPa}$ \\
\hline Poisson's ratio $\left(v_{\mathrm{xy}}, v_{\mathrm{yz}}, v_{\mathrm{xz}}\right)$ & $0.11,0.22,0.22$ & $0.25,0.25,0.25$ & $0.2,0.2,0.2$ & $0.3,0.3,0.3$ \\
\hline Shear modulus $\left(G_{x y}, G_{y z}, G_{x z}\right)$ & $\begin{array}{c}1800 \mathrm{MPa}, 1800 \mathrm{MPa} \\
750 \mathrm{MPa}\end{array}$ & $\begin{array}{c}50 \mathrm{MPa}, 50 \mathrm{MPa} \\
50 \mathrm{MPa}\end{array}$ & $\begin{array}{c}10.4 \mathrm{GPa}, 10.4 \mathrm{GPa} \\
10.4 \mathrm{GPa}\end{array}$ & $\begin{array}{c}79 \mathrm{GPa}, 79 \mathrm{GPa}, \\
79 \mathrm{GPa},\end{array}$ \\
\hline Tensile strength (MPa) & $690 \mathrm{MPa}$ & $0.6 \mathrm{MPa}$ & $1.20 \mathrm{MPa}$ & $235 \mathrm{MPa}$ \\
\hline Compression strength $(\mathrm{MPa})$ & $317 \mathrm{MPa}$ & $0.8 \mathrm{MPa}$ & $20.4 \mathrm{MPa}$ & $235 \mathrm{MPa}$ \\
\hline
\end{tabular}

aggregates with a maximum nominal size of $30 \mathrm{~mm}$. After that, the aggregates were separated according to their dimension, by mechanical sieving, and only the diameter between $5 \mathrm{~mm}$ and $20 \mathrm{~mm}$ was used. After determining the basic performance indexes such as void ratio, water absorption rate, and apparent density of recycled coarse aggregate, the mix design was determined (Table 2). Standard concrete test blocks are produced in the laboratory 
TABLE 2: Recycled aggregate concrete composition.

\begin{tabular}{lc}
\hline Items & Composition \\
\hline P.O 32.5 cement $\left(\mathrm{kg} / \mathrm{m}^{3}\right)$ & 476 \\
River sand $\left(\mathrm{kg} / \mathrm{m}^{3}\right)$ & 742.5 \\
Coarse aggregate $\left(\mathrm{kg} / \mathrm{m}^{3}\right)$ & 1090.5 \\
Water $\left(\mathrm{l} / \mathrm{m}^{3}\right)$ & 191 \\
W/C ratio & 0.40 \\
\hline
\end{tabular}

according to the Chinese building code [16]. After a 28-day period of wet curing, the material properties of recycled aggregate concrete were tested in the laboratory and the test results are presented in Table 1. According to the construction requirements, a steel-mesh layer is used for reinforcing concrete. The diameter of steel bars is $8 \mathrm{~mm}$ and the space is $200 \mathrm{~mm}$. The mechanical properties of reinforced steel bars are also listed in Table 1.

It is well known that debonding between the core and face sheet is the main failure mode of sandwich composite structural. According to the pull-off testing of the three kinds of adhesives for EPS core and GFRP face sheet, epoxy spray adhesive was the most cost-effective candidate adhesive [2]. Thus, the epoxy spray adhesive was chosen for bonding the bottom GFRP face sheet and EPS core in this paper. The adhesive used in ICSIPs is a two-component hightemperature adhesive based on epoxy resin. This adhesive was purchased from USA Osborne (China) Co., Ltd., and the performance specifications of the material are shown in Table 3.

\section{Experimental Investigations}

3.1. Specimen Preparations and Test Setup. Five specimens were produced in the laboratory and the production process is shown in Figure 2. At first, the EPS core was bonded to the bottom GFRP face sheet using the adhesive. Then, a layer of steel mesh was setup on the top of the EPS core. Finally, the recycled aggregate concrete was cast. After curing for 28 days, the ICSIPs were finished. The standard concrete blocks were made for measuring the material properties which are shown in Table 1. The dimension of the specimen is shown in Figure 1 which is the same with traditional SIPs used in the modular buildings nowadays [10].

The experimental testing was performed according to the ASTM E-72-5 standard [17]. And the load was applied at the one-third and two-thirds span of the specimen through a $100 \mathrm{kN}$ SHIMDZU universal testing machine with a loading rate of $2 \mathrm{~mm} / \mathrm{min}$. Figure 3 shows the actual test setup for the flexural test of ISCIPs. Electric resistance strain gauges were used to monitor longitudinal strains in the tension and compression skins at midspan along the two center lines of the specimen. A displacement transducer with sensitivity $0.1 \mathrm{~mm}$ was used to record the midspan deflections, which were recorded by the testing machine automatically.

3.2. Experimental Results. The load-deflection relationship is meaningful to reflect the flexural bearing capacity of ICISPs.
Table 3: Performance specifications of the epoxy adhesive.

\begin{tabular}{lc}
\hline Items & Parameters \\
\hline Viscosity (cps) & 103000 \\
Curing time (h) & 24 \\
Shore hardness & $75 \pm 2$ \\
Glass transition temperature $\left({ }^{\circ} \mathrm{C}\right)$ & 170 \\
Shear strength $(\mathrm{MPa})$ & $\geq 250$ \\
Compressive strength $(\mathrm{MPa})$ & $\geq 5$ \\
Tensile strength $(\mathrm{MPa})$ & $\geq 2.5$ \\
\hline
\end{tabular}

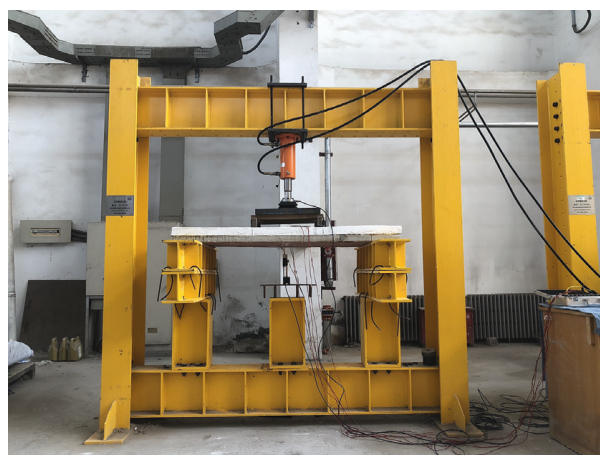

FIGURE 3: Experimental setup for the test.

The experimental results of the five test pieces are basically the same. And the average of the results of the five test pieces was calculated to evaluate the mechanical properties of the ICISPs. As seen from Figure 4, the load-deflection curve for the experimental panels can be divided into three stages. In stage $\mathrm{I}$, the curve is linear. The load is $15.8 \mathrm{kN}$ in the end of stage I and the corresponding displacement is $3.9 \mathrm{~mm}$. Then in stage II, the characteristic of nonlinear can be observed. The load arrives the peak value at $27.7 \mathrm{kN}$ with a midspan deflection of $8.8 \mathrm{~mm}$. Before the load reaches the peak value, cracks can be observed at the recycled aggregate concrete top skin at the end of stage II. The debonding between recycled aggregate concrete face sheet and EPS core appears at the end of the stage II. In stage III, the deflection keeps increasing but the load decreases. It can be observed that the concrete is crushed in this stage. And the ICISPs reach the ultimate bearing capacity.

Figure 5 shows the typical failure states of the ICSIPs. The results of the experiments show that the specimen fails in a brittle manner due to the crush of concrete. The appearance of the initial cracks and the crack propagation in the concrete layer can be observed during this stage with the expansion of the crack debonding between the recycled aggregate concrete faces and EPS core happens. There is no debonding between EPS core and GFRP face sheet, and there is no visible failure of the bottom face sheet. In the end of stage III, the recycled aggregate concrete top skin is crushed fully and the deflection arrives to $164 \mathrm{~mm}$. But the bottom skin showed good capacity of large deformation.

The tensile and compressive strains are recorded from the strain gauges attached to the ICSIPs specimen, as plotted in Section 6.2. The results show that the longitudinal strains of GFRP skin and recycled aggregate concrete skin increase linearly with load before any failure is observed. This shows 


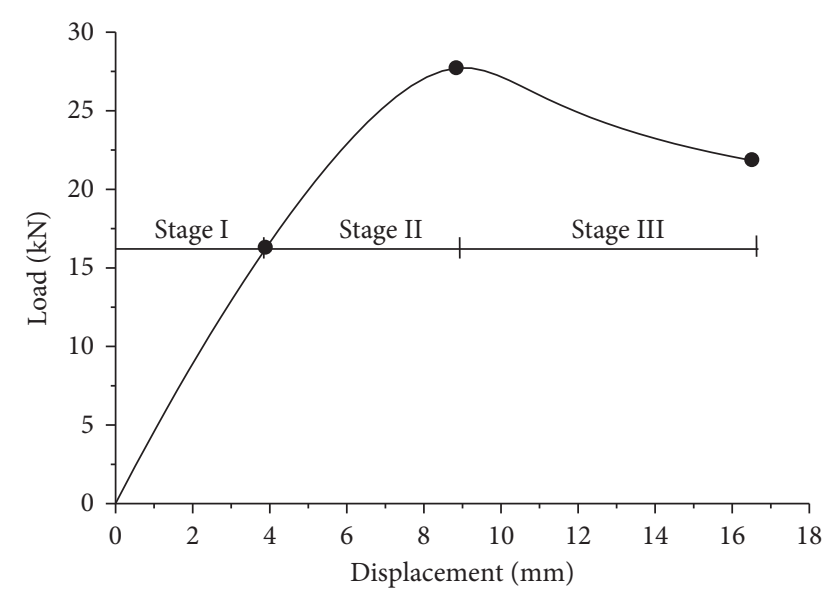

Figure 4: Load-deflection in the midspan position.

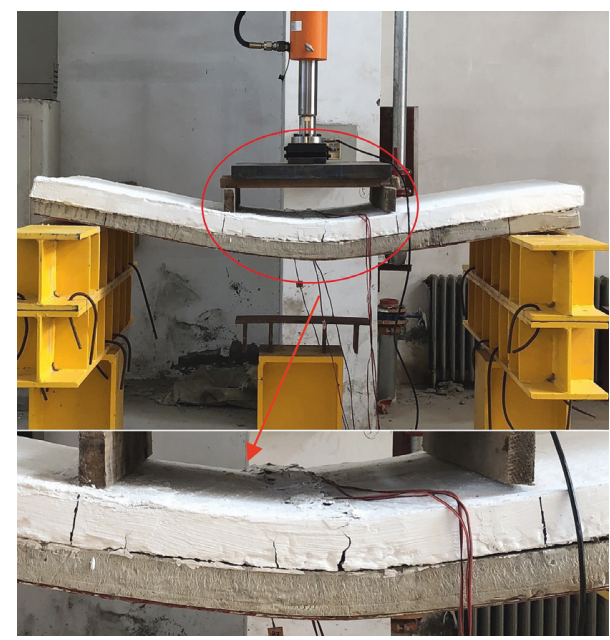

Figure 5: Typical failure mode of the ICSIPs.

the elastic behavior of ICSIP floor panels. When the specimen fails, the tensile strain in the bottom GFRP skin is 0.000972 and the compressive strain in the top concrete skin is 0.000442 .

\section{Investigation by Numerical Simulation}

4.1. Finite-Element Models. The ICSIPs in this paper were analyzed using the universal finite-element software ANSYS [18]. The structural scheme of the panel is $2.4 \mathrm{~m}$ in span and $140.04 \mathrm{~mm}$ in thickness referring to the CSIP [10]. The materials of the core and the bottom GFRP skin of ICSIP are the same to those of CSIP. The panel is constrained on simple supports. The loads are applied on the nodes at one-third and two-thirds span of the top layer to simulate the testing situation.

The properties of all materials are listed in Table 1. Standard Solid45 element of the ANSYS element library is used for the models of the EPS core and the GFRP skin, and Solid65 element is used to simulate the recycled aggregate concrete $[15,19,20]$. This element is capable of simulating plastic deformation, calculating cracking in three orthogonal directions, and judging crushing. In ICSIPs models, there is no relative movement between face sheets and EPS foam cores as they are glued together. Ideal linear elastic relationships are assumed for the GFRP and EPS foam. Multilinear stress-strain relationship for recycled aggregate concrete is adopted (Figure 6) because both cracking and crushing failure modes are accounted for. The shear transfer coefficient introduced into the crack model is 0.3 [21-24]. Reinforcement steels are discredited into elements, and the effects of reinforcing are averaged within the pertaining element. Cracks are idealized into the smeared type. 19800 elements are required for the ICSIPs model because the face sheets are very thin and the materials are different between face sheets and core.

4.2. Static Analysis. Based on the previously described finiteelement model, numerical calculations with ANSYS were conducted. The experimental limit load $27.7 \mathrm{kN}$ is averaged and applied at the loading points in addition to structural dead weight. The results of linear static analysis are summarized in Figure 7.

The maximum vertical displacement of the ICSIP is $7.76 \mathrm{~mm}$. It is about $1 / 309$ the span and can satisfy the requirement of codes with surplus. If only gravity is considered, the displacement is $0.09 \mathrm{~mm}$. This proportion in the total displacement is about $1.2 \%$. It shows that the structural self-weight is light relatively.

From the side-by-side comparison of stresses in three components of ICSIPs (Figure 7), it can be observed that the maximum stress of GFRP face sheet is $11.5 \mathrm{MPa}$, which occurs at the middle span. It is much less than the allowable stress of GFRP. The maximum stress of the EPS foam at the middle span is much smaller, only $0.01 \mathrm{MPa}$. But the maximum stress reaches $0.62 \mathrm{MPa}$ at the region besides supports. The compression stress in recycled aggregate concrete is 6.77 $\mathrm{MPa}$ at the middle span, much less than the allowable stress. However, the maximum stress of the recycled aggregate concrete is tensile $2.02 \mathrm{MPa}$ at the middle span. It shows the tensile stress is dramatic even if the panel bends downwards. The value of the tensile stress is beyond the allowable stress and cracks occur, so it is necessary to carry on the geometrical nonlinear analysis considering the development of cracks in recycled aggregate concrete.

4.3. Nonlinear Analysis. Nonlinear buckling analysis can satisfy the real-world situation such as large deflection, initial imperfection, and cracks better [15]. A nonlinear constitutive relationship of recycled aggregate concrete was adopted (Figure 6), while the GFRP face sheet and EPS core still use linear elastic constitutive relationship because their maximum stress is much less than their allowable values. The Newton-Raphson equilibrium iteration method was activated, and stress stiffness was considered. Convergence criteria were based on force and displacement, and the convergence tolerance limits were initially selected by the ANSYS program.

The results obtained from finite-element models are summarized in Figure 8. It can be observed that the initial cracking of the panel in the FE model corresponds to a load of $16.4 \mathrm{kN}$. At this time the, stress is just beyond $1.20 \mathrm{MPa}$, the modulus of rupture of the recycled aggregate concrete. 


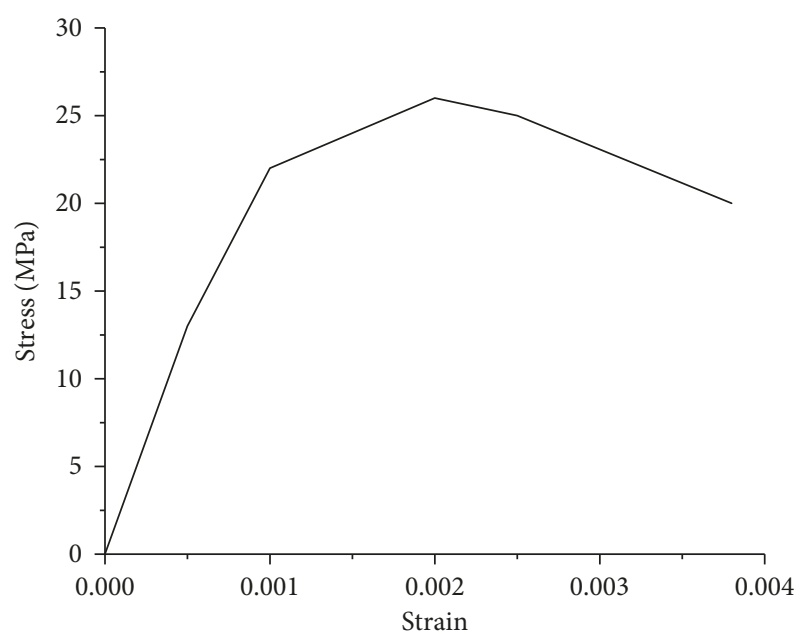

FIGURE 6: Stress-strain relationship of recycled aggregate concrete.

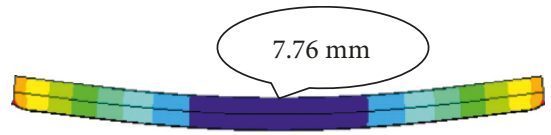

(a)

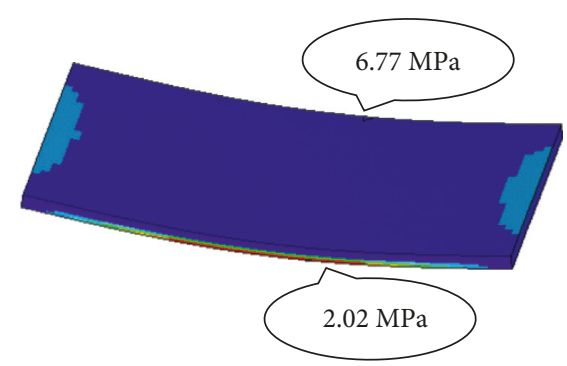

(b)

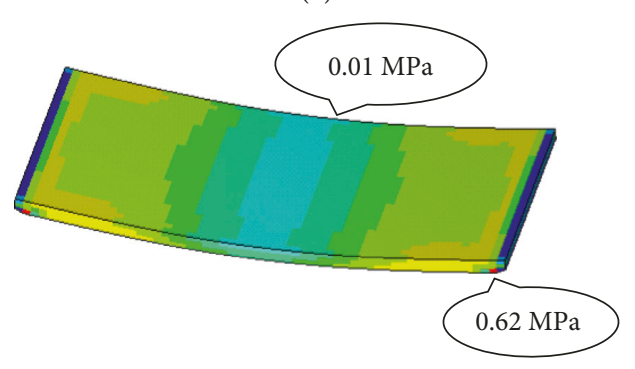

(c)

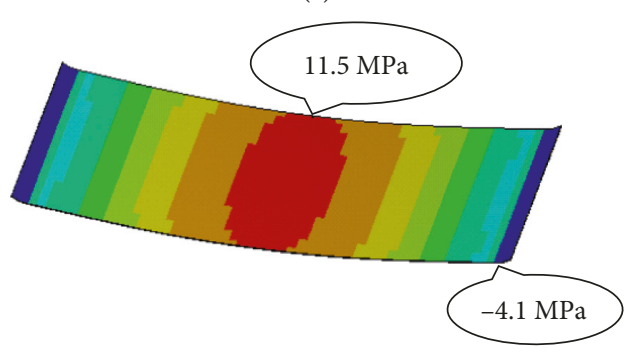

(d)

Figure 7: Results of static analysis: (a) structural displacement; (b) stress in the recycled aggregate concrete layer; (c) stress in the EPS core; (d) stress in the GFRP skin.

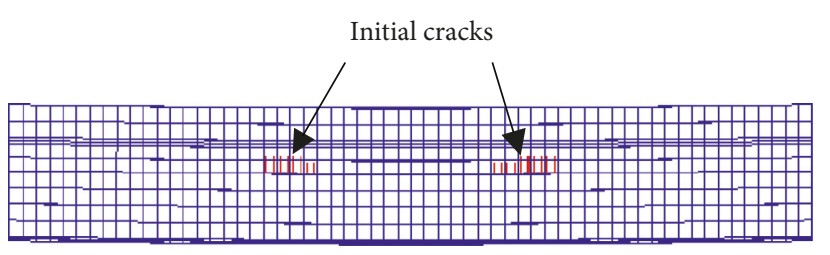

(a)

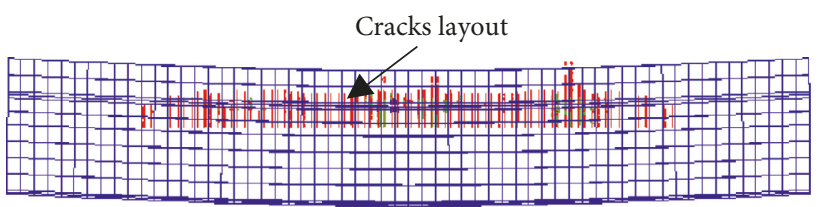

(b)

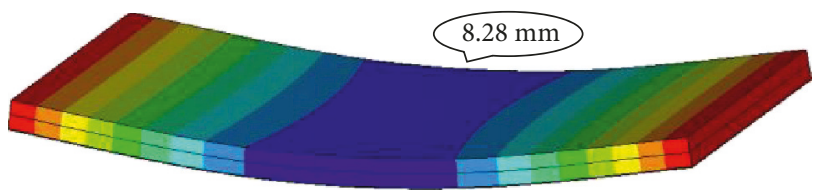

(c)

FIGURE 8: Results of nonlinear analysis: (a) crack appears; (b) cracks layout at limit state; (c) structural deformation.

This agrees well with the load of the experiment. The initial crack can be seen to occur in the constant moment region in the middle one-third span, and it is a flexural crack.

Subsequently, cracks expand as the load increases, and these cracks extend out from the initial one. Displacements of the panel begin to increase at a higher rate with the increase of the load. The characteristic of nonlinear is obvious from the load-displacement curve. At $29.4 \mathrm{kN}$, one crack has reached the top of the panel and failure is soon to follow. At last, a few severe cracks throughout the entire thickness arise, and the compressive stress in concrete has been beyond the ultimate strength. The panel can no longer bear the additional load as indicated by an insurmountable convergence failure. In the last stage, it shows the crushing of recycled aggregate concrete. The maximum displacement at midspan is $8.28 \mathrm{~mm}$.

\section{Theoretical Evaluation of the Flexural Response}

5.1. Analysis of Load Bearing Capacity. Figures 1 and 9 show the geometrical characteristic and details of the test specimen. The width is $B=1200 \mathrm{~mm}$, the depth is $H=$ $143.04 \mathrm{~mm}$, and the test span is $L=2400 \mathrm{~mm}$. The depth of the top recycled aggregate concrete layer is $t_{1}=70 \mathrm{~mm}$, the depth of the EPS core is $t_{2}=70 \mathrm{~mm}$, and the depth of the GFRP layer is $t_{3}=3.04 \mathrm{~mm}$. The distance between the recycled aggregate concrete of the top layer and the core is $d_{1}=70 \mathrm{~mm}$, and the distance between the center of the core and the bottom layer is $d_{2}=36.52 \mathrm{~mm}$.

The failure mode of ICSIPs is the crack of the recycled aggregate concrete top skin when the applied load reaches the ultimate strength. The classical theory of sandwich panels provides the calculation formula corresponding to this failure mode [3, 25-29]. 


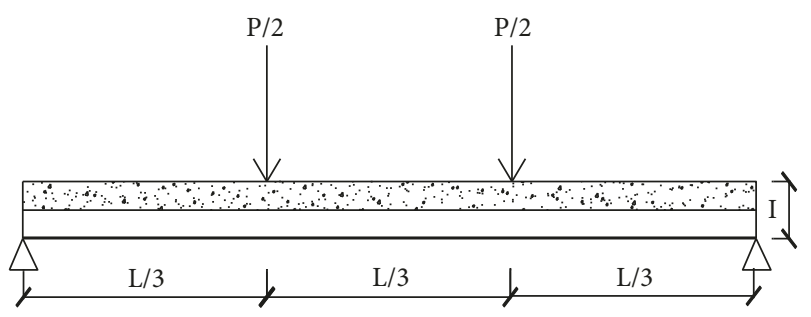

(a)
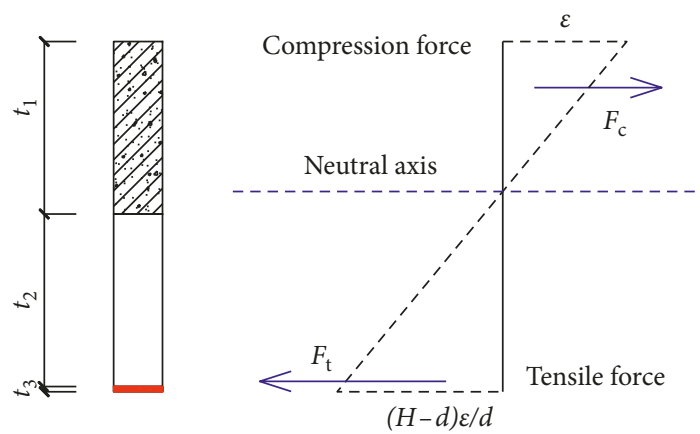

(b)

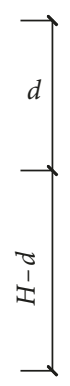

FIGURE 9: Force diagram: (a) schematic illustration the loading; (b) forces for cross section.

$$
\sigma_{1}=\frac{M}{W}=\frac{M H}{2 \mathrm{EI}} E_{1}
$$

where $\sigma_{1}$ is the bending strength of the concrete compressive skin, $M$ is the moment about the neutral axis, $W$ is the flexural section factor, $E_{1}$ is the elasticity modulus of the recycled aggregate concrete compressive skin, and $I$ is the second moment of the neutral axis of the composite sandwich section. EI is the flexural stiffness of the entire section. Then the crest value of the load $P$ can be expressed by the following equation:

$$
P=\frac{12 \mathrm{EI} \sigma_{1}}{L E_{1} H}=\frac{\mathrm{EB} \sigma_{1}}{L E_{1}} .
$$

And the flexural stiffness of ICSIPs was calculated using the sum of the flexural stiffness of the constituent parts about the center axis of the entire section. It can be obtained by the following equation:

$$
\begin{aligned}
\mathrm{EI}= & \frac{B t_{1}^{3}}{12} E_{1}+B t_{1}\left(d-\frac{1}{2} t_{1}\right)^{2} E_{1}+\frac{B t_{2}^{3}}{12} E_{2}+B t_{2}\left(\frac{3}{2} t_{2}-d\right)^{2} E_{2} \\
& +\frac{B t_{3}^{3}}{12} E_{3}+B t_{3}\left(H-d-\frac{1}{2} t_{3}\right)^{2} E_{3},
\end{aligned}
$$

where $E_{2}$ and $E_{3}$ are the modulus of elasticity of the core and the bottom skin, respectively, and $d$ is the distance between compression force line and the neutral axis (Figure 9), and it can be obtained by the following equation:

$$
\frac{d}{2} \varepsilon E_{1}=F_{c}=F_{\mathrm{t}}=\frac{\varepsilon E}{2 d \eta}(H-d)^{2}
$$

where $E$ is the equivalent modulus of elasticity of the entire section and $\eta$ is the reduction factor of the equivalent elastic modulus. And considering the stress state of the ICSIPs, $\eta$ takes 0.57 .

5.2. Analysis of Deflection. In ICSIPs, the shear stiffness of EPS core is very low compared with the face sheets, so the shear deformation should be accounted in the total deflection. And the total deformation of the ICSIPs can be predicted as the sum of bending and the shear deflections:

$$
\Delta=\Delta_{\mathrm{b}}+\Delta_{\mathrm{s}}
$$

where $\Delta, \Delta_{\mathrm{b}}$, and $\Delta_{\mathrm{s}}$ indicate the total deflection, deflection owing to bending, and deflection owing to shear, respectively.

As we know, the deflection at the midspan of the beam is the maximum for a simply supported beam under four-point static bending. So, the total deflection can be calculated by the following equation, which is based on the principle of virtual work from the classical structural analysis:

$$
\Delta=\int \frac{M_{\mathrm{p}} \bar{M}}{\mathrm{EI}} d x+\int \frac{k Q_{\mathrm{p}} \overline{\mathrm{Q}}}{\mathrm{GA}} d x,
$$

where $M_{\mathrm{p}}$ and $\mathrm{Q}_{\mathrm{p}}$ indicate the bending moment and the shear due to the load and $\bar{M}$ and $\bar{Q}$ indicate the bending moment and shear due to the unit load at the midspan. GA is referred to as the shear stiffness of the sandwich beams, and $k$ is the shear correction factor.

Therefore, the deflection can be calculated by integrating the deflection along the beam as follows:

$$
\begin{aligned}
& \Delta_{\mathrm{b}}=2 \times \frac{P L}{6 \mathrm{EI}} \times\left(\int_{0}^{L / 3} \frac{3 x^{2}}{2 L} d x+\int_{L / 3}^{L / 2} \frac{x}{2} d x\right)=\frac{23 P L^{3}}{1296 \mathrm{EI}}, \\
& \Delta_{s}=2 \times \frac{K}{\mathrm{GA}} \int_{0}^{L / 3}\left(\frac{P}{2} \times \frac{1}{2}\right) d x=\frac{K P L}{6 \mathrm{GA}} .
\end{aligned}
$$

For the specimen with a rectangular section, the shear correction factor $K$ is 1.2 . In the end, the total deflection at the midspan can be obtained:

$$
\Delta=\frac{23 P L^{3}}{1296 \mathrm{EI}}+\frac{P L}{5 \mathrm{GA}} \text {. }
$$

\section{Comparison and Discussion}

The analysis of results comparison between the theoretical prediction, numerical simulations, and experimental testing is discussed in this section.

6.1. Discussions on Load-Deflection Curves. The comparison of the theoretical analytical, numerical and experimental loads, and midspan deflection curves for ICSIPs tested under four-point bending is shown in Figure 10. To describe the average difference between the experimental data points and the mean, we added standard deviation information in the form of error bars. Overall, the theoretical results are in good agreement with the experimental and numerical results. The theoretical predictions reflect well the linear flexural response of the ICSIPs, while deviate as the load 


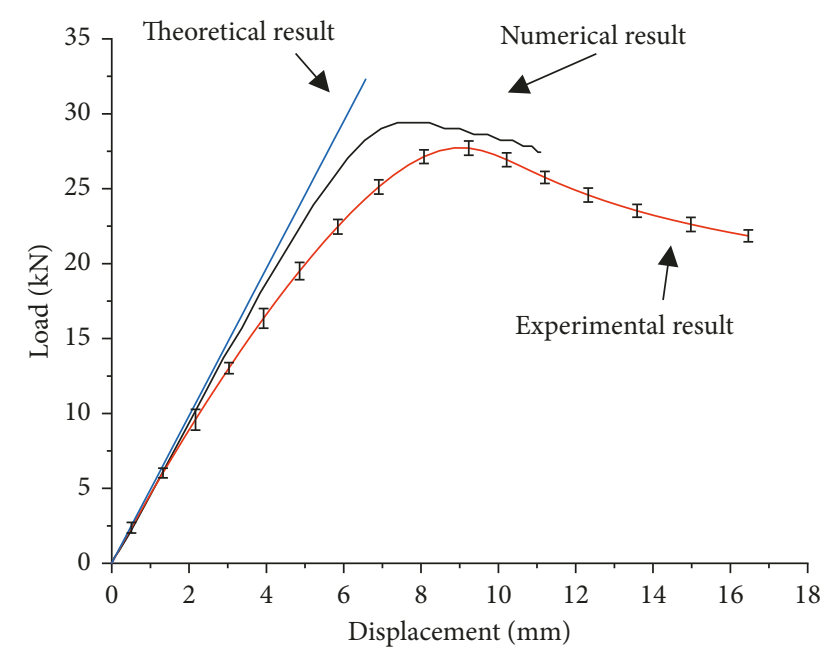

Figure 10: The load-deflection relation curves of the experimental (mean $\pm \mathrm{SD}, n=5$ ), numerical, and theoretical results.

increases up to failure due to the theory limitations. The load increases linearly with deflection until the load reaches the maximum values. Then, the obvious decrease of stiffness is seen due to the appearance of cracking of the top recycled aggregate concrete skin. The cracks extend along the thickness of the top skin, which leads to dramatic increase of deflection.

The maximum load of experiment is $27.7 \mathrm{kN}$. However, the theoretical peak value of the load is $32.3 \mathrm{kN}$ which is $16.6 \%$ larger than the experimental results. Correspondingly, the maximum deflection of theoretical results is $6.72 \mathrm{~mm}$, which is $13.4 \%$ smaller than the experimental results. The reason is owing to the assumption of linear elastic behavior of materials.

The FE analysis considering the double nonlinear behavior of material and geometry provides the process of failure in good agreement with the experiments. The numerical value of the maximum load is $29.4 \mathrm{kN}$, which is a little larger than that of the experimental result. And the corresponding deflection of midspan is $8.28 \mathrm{~mm}$, which is a little smaller than that of the experimental result. The small divergence between the experimental and numerical results is attributed to two reasons. One is the effect of the debonding phenomenon was not considered in the FE analysis, and the other is the errors during the manufacture and test of specimen.

6.2. Discussions on Load-Strain Relationship. Figure 11 shows the comparison of the load-strain relationship between the numerical and experimental results (mean \pm SD, $n=5$ ). The linear relationship can be observed in both the tension and compression skins. The numerical and experimental results have good agreement. The good match between the experimental and the simulated response of the ICSIPs indicated the good interaction between the core and double skins.

6.3. Failure Mode. The experimental results showed that the failure mode of the specimen under four-point

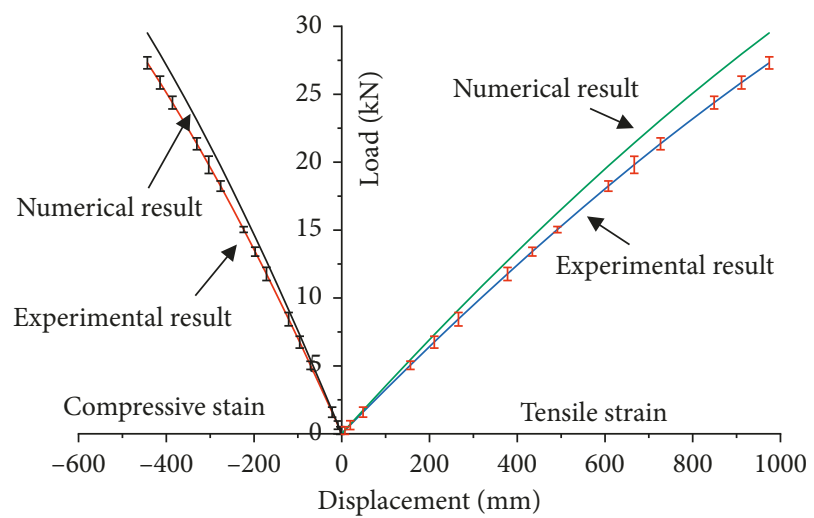

FIgURE 11: Load-strain relationships. The bar graphs are presented as mean $\pm \mathrm{SD}(n=5)$.

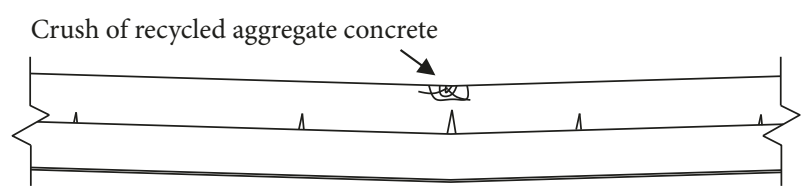

(a)

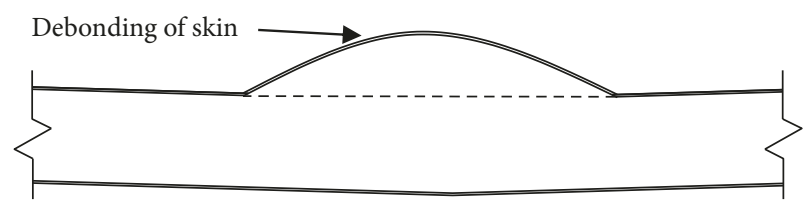

(b)

FIGURE 12: Failure modes of ICSIP and CSIP: (a) crush of recycled aggregate concrete for ICSIP; (b) debonding of skin for CSIP.

bending test is the compressive failure of the top recycled aggregate concrete skin. The failure mechanism analysis from the FE analysis is shown in Figure 12. The maximum stress in the top recycled aggregate concrete skin reaches the critical value, while the stress in the bottom GFRP skin is far less than their allowable value. The cracks appear at the bottom of the concrete layer at the midspan and extended upwards quickly until the crush of the recycled aggregate concrete layer. When the specimen reached the ultimate load, the debonding occurs between the top recycled aggregate concrete face sheet and the EPS core due to crushing of the recycled aggregate concrete face sheet. However, there is no debonding between EPS core and GFRP face sheet. In all specimens, the failure mechanisms predicted from the FE simulations are similar to the failure mechanisms observed in the experimental investigation.

6.4. Comparison with the CSIPs. The research results of the improved CSIPs in this paper show three obvious differences from CSIPs [10]. The first is the load bearing capacity of ICSIP 3.46 times of that of CSIP. The frontier is $27.7 \mathrm{kN}$ while the latter is $8 \mathrm{kN}$. It shows that ICSIP is strong enough to bear the load $7.6 \mathrm{kN} / \mathrm{m}^{2}$ except of self-weight when they are used in floors with the span $2.4 \mathrm{~m}$. 
The second is that the maximum deflection of ISCIP $(8.8 \mathrm{~mm})$ is about 6 times smaller than that of CSIP $(52 \mathrm{~mm})$. The deformation of $1 / 273$ of the span shows that it can satisfy the requirement of stiffness when they are used in floors or roofs.

The third is that the failure mode of ICSIP is different from that of CSIP (Figure 12). The frontier is the crush of the top recycled aggregate concrete layer. However, the latter is the debonding between the compression face sheet and the core which causes the face sheet wrinkling failure and the core shear failure immediately.

6.5. Comparison with the Recycled Aggregate Concrete Panel. If only the recycled aggregate concrete top layer is kept while the EPS core and the bottom GFRP skin are moved away, the limit load is $2.8 \mathrm{kN}$. Even if enough reinforced steel bars are set inside to abide by the building codes for panels, its ultimate load is no more than $12.5 \mathrm{kN}$. It shows the ICSIP is much stronger than the recycled aggregate concrete panel with nearly the same self-weight. The sandwich structure of ICSIP has much larger moment resistance stiffness by enhancing thickness of the panel. And advantages of compressive concrete and tensile GFRP materials are made full use. The sandwich structure of ICSIP can also be used for reference to strengthen the damaged concrete floors or roofs in service.

\section{Conclusions}

New improved composite structural insulated panels (ICSIPs) were presented for the structural floor of roof applications in this paper. A full-scale experimental test of four-point bending was investigated. The FE analysis was conducted based on the ANSYS program. And theoretical formulas were also developed to calculate the ultimate bearing load and deflection. The main conclusions from this study can be summarized as follows:

(1) The ICSIPs are applicable for building floors or roofs with enough structural strength and stiffness in comparison with CSIPs. The ICSIPs can overcome the two shortcomings of CSIPs; one is the large deflection, and the other is the low bearing capacity. It is especially suitable for large-span roofs owing to excellent thermomechanical properties and superior durability except of high strength.

(2) The general mode of failure of ICSIPs was the crush of the top recycled aggregate concrete layer at the midspan.

(3) The nonlinear FE analysis is effective in the engineering design of ICSIPs in engineering practice. And the theoretical predictions reflect well the linear flexural response of the ICSIPs, while deviates as the load increases up to failure due to the theory limitations.

(4) ICSIPs are strong enough to bear heavy loads. From the analysis of stiffness, it is still the requirement of deflection that controls the design of
ICSIPs. Therefore, the strength of the recycled aggregate concrete is feasible as the top face sheet in ICSIPs, and it is conducive to save resources and to protect the environment.

\section{Data Availability}

The data used to support the findings of this study are available from the corresponding author upon request.

\section{Conflicts of Interest}

The authors declare that they have no conflicts of interest.

\section{Authors' Contributions}

QL designed and performed the experiments, as well as drafted the manuscript. WD have carried the literature study and participated in experiments design and result discussions. NU provided some advices on the manuscript. ZZ performed the experimental works. All authors read and approved the final manuscript.

\section{Acknowledgments}

The authors would like to express sincere thanks to Yun Sun., Zhihao Du., and Shuailiang Zhang., for supporting the fabrication of test specimens. This research was supported by the National Science Foundation (NSF) (CMMI-0825938) and National Science Foundation of China (NSFC) (U1704141).

\section{References}

[1] C. G. Weber, "Fiber building boards," Journal of Industrial and Engineering Chemistry, vol. 27, no. 8, pp. 896-898, 1935.

[2] N. Uddin, A. Vaidya, U. Vaidya, and S. Pillay, "Thermoplastic composite structural insulated panels (CSIPs) for modular panelized construction," Developments in Fiber-Reinforced Polymer (FRP) Composites for Civil Engineering, vol. 12, pp. 302-316, 2013.

[3] H. G. Allen and B. G. Neal, Analysis and Design of Structural Sandwich Panels, Elsevier, Amsterdam, Netherlands, 1969.

[4] M. Morley, Building with Structural Sandwich Pannel, The Taunton Press, Newtown, CT, USA, 2000.

[5] J. M. Davies, Lightweight Sandwich Construction, University of Manchester press, Manchester, UK, 2001.

[6] N. Uddin, A. Vaidya, N. Uddin, and U. Vaidya, "Design and analysis of composite structural insulated panels (CSIPs) for exterior wall applications," Journal of Composites for Construction, vol. 14, no. 4, pp. 1313-1322, 2010.

[7] N. M. Long, D. Vo-Le, D. Tran-Thanh, T. M. Pham, C. HoHuu, and M. Rovñák, "Shear capacity of unbonded posttensioned concrete T-beams strengthened with CFRP and GFRP U-wraps," Composite Structures, vol. 184, pp. 10111029, 2018.

[8] G. Boscato and S. Ientile, "Experimental and numerical investigation on dynamic properties of thin-walled GFRP buckled columns," Composite Structures, vol. 189, pp. 273285, 2018

[9] D. Y. Yoo, N. Banthia, and Y. S. Yoon, "Flexural behavior of ultra-high-performance fiber-reinforced concrete beams 
reinforced with GFRP and steel rebars," Engineering Structures, vol. 111, pp. 246-262, 2016.

[10] M. A. Mousa and N. Uddin, "Flexural behavior of full-scale composite structural insulated floor panels," Advanced Composite Materials, vol. 20, no. 6, pp. 547-567, 2011.

[11] M. A. Mousa and N. Uddin, "Structural behavior and modeling of full-scale composite structural insulated wall panels," Engineering Structures, vol. 41, pp. 320-334, 2012.

[12] N. Uddin and W. Du, "New thin shells made of composite structural insulated panels," Journal of Reinforced Plastics and Composites, vol. 33, no. 21, pp. 1954-1965, 2014.

[13] M. A. Mousa and N. Uddin, "Debonding of composites structural insulated sandwich panels," Journal of Reinforced Plastics and Composites, vol. 29, no. 12, pp. 33803391, 2010.

[14] N. Uddin, M. Mousa, and N. Uddin, "Performance of composite structural insulated panels (CSIPs) after exposure to floodwater," Journal of Performance of Constructed Facilities, vol. 27, no. 4, pp. 424-436, 2010.

[15] W. Du and N. Uddin, "Innovative composite structural insulated panels (CSIPs) folded shell structures for large-span roofs," Materials and Structures, vol. 50, no. 1, p. 51, 2017.

[16] Ministry of Housing and Urban-Rural Construction of the People's Republic of China, Standard for Evaluation of Concrete Compressive Strength, AQSIQ, China, 2010.

[17] Annual Book of ASTM Standards E-72-05, Standard Test Method of Conducting Strength Tests of Panels for Building Construction, 100 Barr Harbor Drive, West Conshohocken, PA, USA, 2005.

[18] ANSYS, ANSYS 11.0 Manual Set, ANSYS Inc., Canonsburg, PA, USA, 2008.

[19] J. Tejchman and J. Bobiński, Continuous and Discontinuous Modelling of Fracture in Concrete Using FEM, Springer, Berlin, Germany, 2013.

[20] C. Borsellino, L. Calabrese, and A. Valenza, "Experimental and numerical evaluation of sandwich composite structures," Composites Science and Technology, vol. 64, no. 10-11, pp. 1709-1715, 2004.

[21] F. Y. Li, L. Y. Li, Y. Dang, and P. F. Wu, "Study of the effect of fibre orientation on artificially directed steel fibre-reinforced concrete," Advances in Materials Science and Engineering, vol. 2018, Article ID 8657083, 11 pages, 2018.

[22] N. Grover, D. K. Maiti, and B. N. Singh, "A new inverse hyperbolic shear deformation theory for static and buckling analysis of laminated composite and sandwich plates," Composite Structures, vol. 95, no. 1, pp. 667-675, 2013.

[23] R. Sun, B. Xie, R. Perera et al., "Modeling of reinforced concrete beams exposed to fire by using a spectral approach," Advances in Materials Science and Engineering, vol. 2018, Article ID 6936371, 12 pages, 2018.

[24] S. Mangalathu and J. S. Jeon, "Classification of failure mode and prediction of shear strength for reinforced concrete beam-column joints using machine learning techniques," Engineering Structures, vol. 160, pp. 85-94, 2018.

[25] J. R. Vinson, The Behavior of Sandwich Structures of Isotropic and Composite Materials, Technomic, Lancaster, PA, USA, 1999.

[26] R. A. Hawileh, H. A. Rasheed, J. A. Abdalla, and A. K. AlTamimi, "Behavior of reinforced concrete beams strengthened with externally bonded hybrid fiber reinforced polymer systems," Materials and Design, vol. 53, no. 1, pp. 972-982, 2014.

[27] H. T. Thai and D. H. Choi, "A simple first-order shear deformation theory for laminated composite plates," Composite Structures, vol. 106, no. 12, pp. 754-763, 2013.
[28] A. J. M. Ferreira, "A formulation of the multiquadric radial basis function method for the analysis of laminated composite plates," Composite Structures, vol. 59, no. 3, pp. 385-392, 2003.

[29] M. M. Kheirikhah, S. M. R. Khalili, and K. M. Fard, "Biaxial buckling analysis of soft-core composite sandwich plates using improved high-order theory," European Journal of Mechanics-A/Solids, vol. 31, no. 1, pp. 54-66, 2012. 


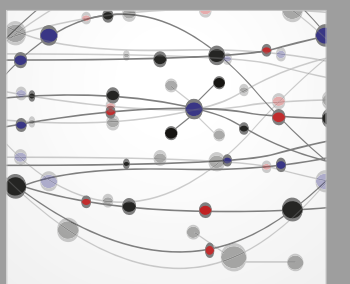

The Scientific World Journal
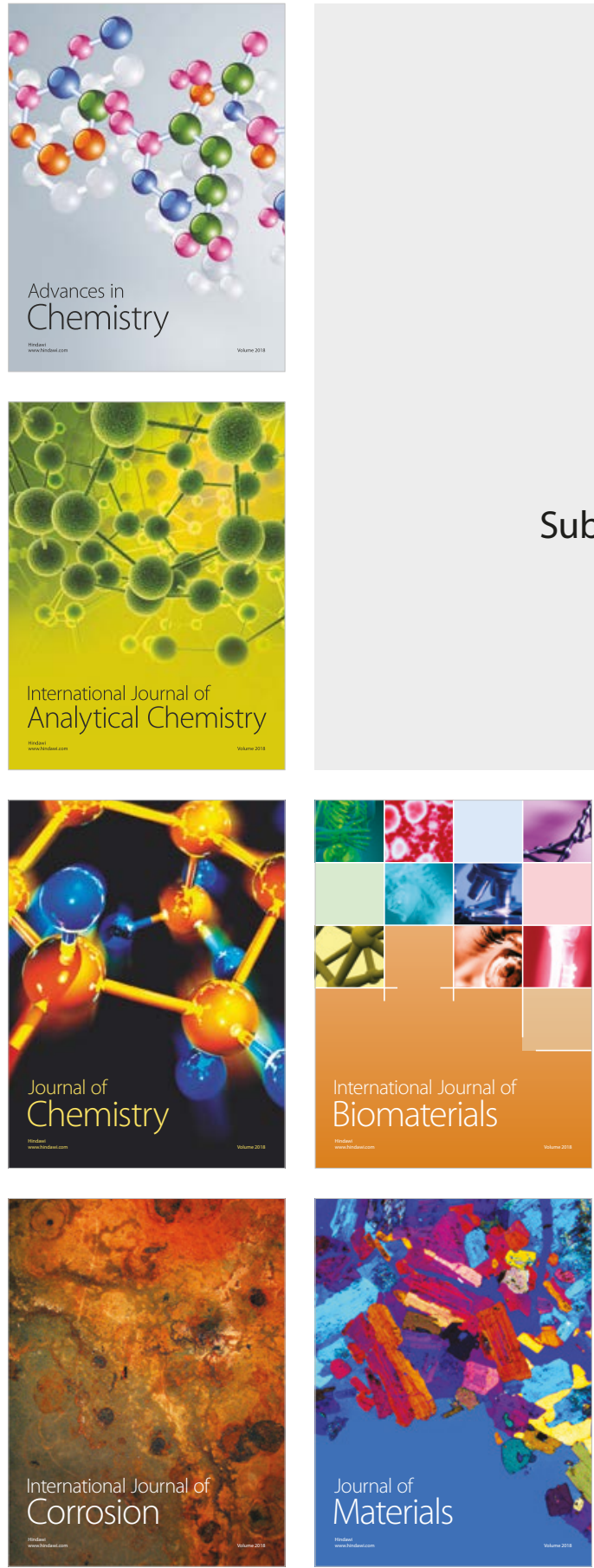

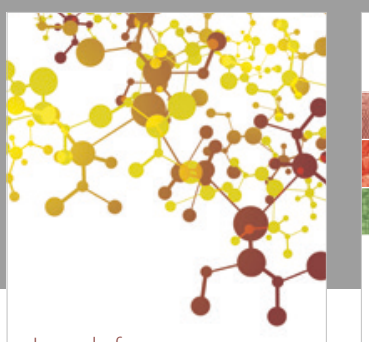

Journal of

Applied Chemistry
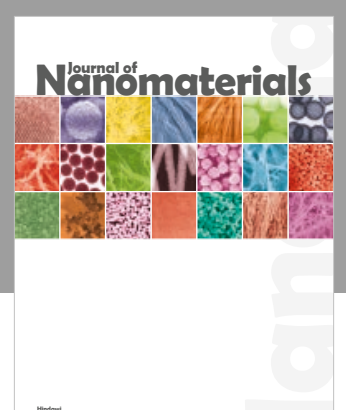

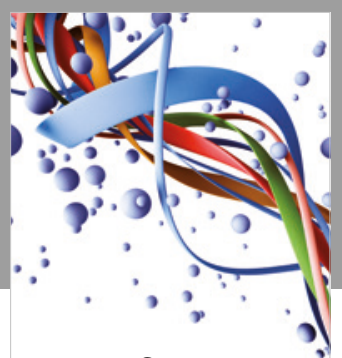

Scientifica

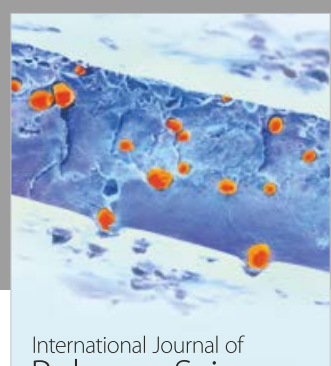

Polymer Science

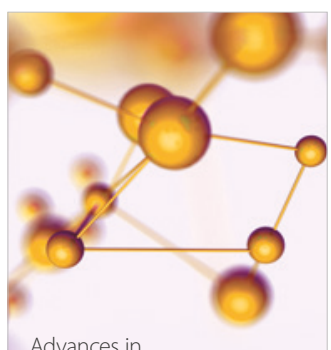

Physical Chemistry
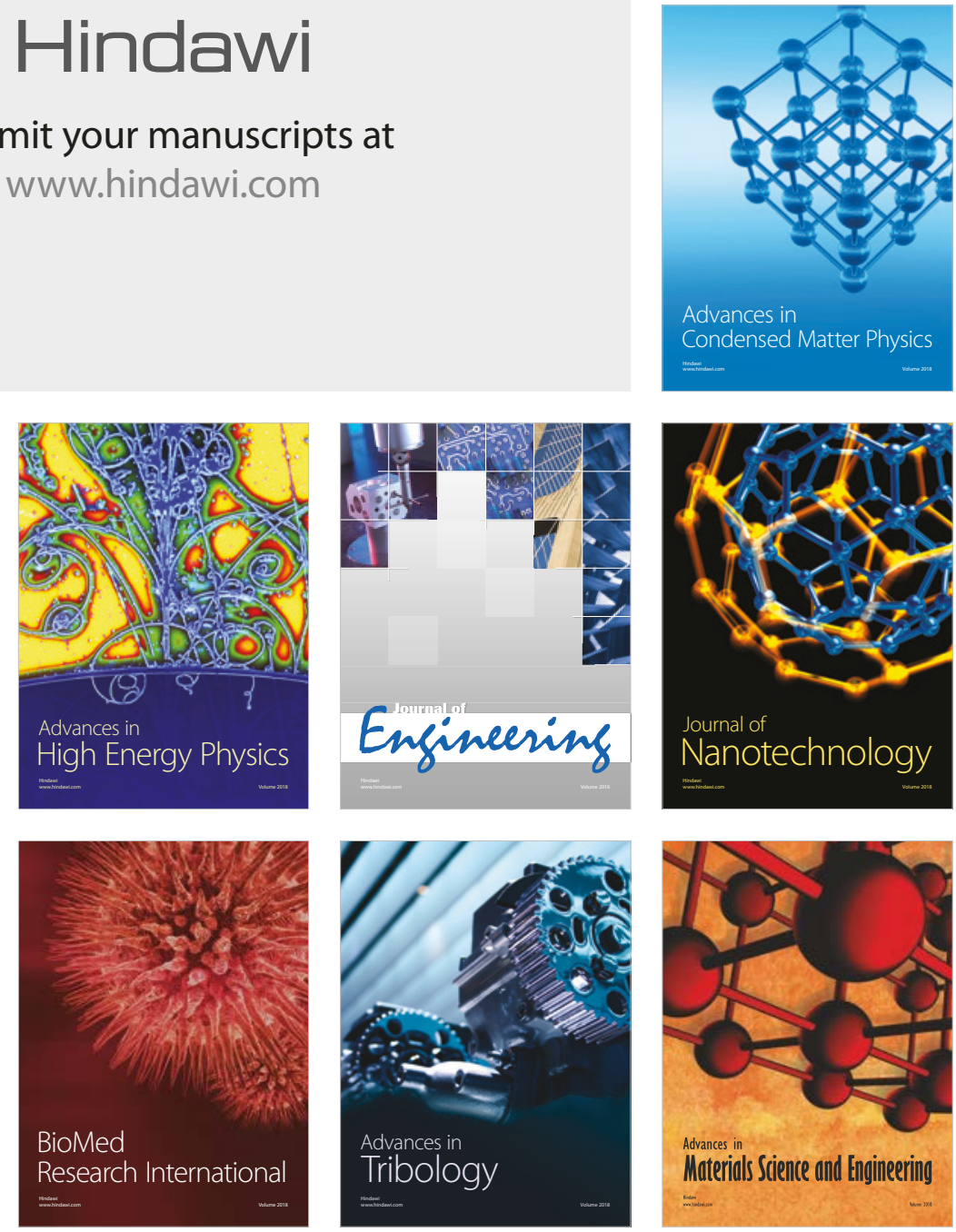